\title{
Eine modifizierte Chloroform-Elutionstechnik für erythrozytäre Antikörper
}

\author{
P. M. Winter \\ Institut für Blütgruppenserologie der Universität Wien * (Vorstand: Prof. Dr. Paul Speiser)
}

\section{Zusammenfassung:}

Durch eine Modifikation der Chloroformelutionstechnik mittels Verwendung von Ammoniumchloridlösung als Waschflüssigkeit wird die Verfärbung des erythrozytären Eluats vermieden und die Eluatmenge vergrößert.

Schlüsselwörter:

Elution - Erythrozyten - Antikörper - Chloroform - Ammoniumchlorid

\section{Summary:}

Using ammonium chloride as a washing solution the chloroform elution technique is modified in order to avoid discoloration of the resulting eluate by haemoglobin and rising its quantity.

\section{Keywords:}

elution - erythrocytes - antibody - chloroform - ammonium-chloride

\section{Einleitung}

Seit der Einführung des thermischen Eluats durch Landsteiner sind weitere Antikörper-Absprengungstechniken bekannt geworden, die in Routine und Forschung Anwendung finden (Tab. 1). Hiervon haben sich in unserem Labor besonders das thermische und das Chloroformeluat bewährt, die gegenüber anderen Methoden die Vorteile der Einfachheit und Sicherheit besitzen.

Ziel dieser Arbeit war es, die Hämoglobinkonzentration im Chloroformeluat soweit zu vermindern, daß das' Erkennen schwacher Agglutinationen im Objektträger- und im Röhrchentest verbessert wird, ohne die Qualität dieser Elutionstechnik zu schmälern.

\section{Material und Methöden}

\section{Sera}

Spezifitäten: Anti-A,B, M,N,D,CD,E,C,e, Fy ${ }^{a}, F^{b}, J^{b}, J^{b}$. Antihumanglobulin: polyspezifisch (Anti-lgG/lgM/Komplement).

Bei der LISS-Technik (Low Jonic Strength Solution) wird eine 0,01 molare Lösung verwendet.

Hersteller-Firmen: Behring, Biotest, Dr. Molter AG., Ortho Diagnostics. Bei den Spezifitäten Anti-A,M,N kamen auch monoklonale Reagenzien zur Anwendung.

\section{Blutproben}

a) Aus klinischem Einsendematerial.

b) Testerythrozyten der Firmen Biotest (Biotestcell I) und Ortho Diagnostics (Resolve Panel A) zur Antikörperspezifizierung.

\footnotetext{
- National Blood Group Reference Laboratory (WHO)

National Tissue Typing Reference Laboratory (Council of Europe)
}

Blutproben (1 Teil) von a) wurden durch Versetzen mit spezifischem Serum (3 Teile) artifiziell mit Antikörpern beladen.

Bei der Elution verwendete Ammoniumchloridlösung
$0,155 \mathrm{~mol} / \mathrm{I} \mathrm{NH}_{4} \mathrm{Cl}$
$0,01 \mathrm{~mol} / \mathrm{I} \mathrm{KHCO}_{3}$
$8,3 \mathrm{~g}$
$1 \times 10^{-4} \mathrm{~mol} / \mathrm{I} \mathrm{Na-EDTA}$
$1,0 \mathrm{~g}$
Aqua dest. ad
$0,037 \mathrm{~g}$
$1000,0 \mathrm{ml}$

$\mathrm{pH} 7,3$ bei $0^{\circ} \mathrm{C}$ mittels $\mathrm{HCl}$ einstellen.

\section{Chloroformeluat (Standard)}

Ein Teil Erythrozyten-Sediment 6-8mal in Phosphate Buffered Saline (PBS) gewaschen versetzt mit 1 Teil PBS in 2 Teilen Chloroform; 1 min kräftig geschüttelt; Inkubation bei $56^{\circ} \mathrm{C}$ im Wasserbad 5 min (mehrmals mit Holz-

Tab. 1 : Antikörper-Absprengungstechniken

\begin{tabular}{|c|c|c|}
\hline $\begin{array}{l}\text { Elutions- } \\
\text { methode }\end{array}$ & Vorteile & Nachteile \\
\hline $\begin{array}{l}\text { Thermisch }\left(56^{\circ} \mathrm{C}\right) \\
\text { (5) }\end{array}$ & $\begin{array}{l}\text { technisch einfach, } \\
\text { ungefährlich }\end{array}$ & weniger sensibel $^{\bullet}$ \\
\hline Chloroform $(1,8)$ & $\begin{array}{l}\text { technisch einfach, } \\
\text { sensibel }\end{array}$ & $\begin{array}{l}\text { stark hämolytisch, } \\
\text { daher Eluat Hä- } \\
\text { moglobin verfärbt }\end{array}$ \\
\hline Äther (9) & sensibel & $\begin{array}{l}\text { explosiv, } \\
\text { hämolytisch, } \\
\text { Eluat = unterste } \\
\text { Schicht }\end{array}$ \\
\hline Säure (4) & sensibel & $\begin{array}{l}\text { Eluat muß oft kon- } \\
\text { zentriert werden }\end{array}$ \\
\hline Kälteschock (3) & sensibel & $\begin{array}{l}\text { nur } f . \text { IgG geeignet, } \\
\text { hämolytisch }\end{array}$ \\
\hline Xylol (2) & sensibel & explosiv \\
\hline
\end{tabular}

- Sensibel, auch bei geringer Antikorpermengu noch deutlich ẹluierbar 
Tab. 2: Titerergebnisse des modifizierten Eluats im Vergleich zur Standardtechnik

\begin{tabular}{|c|c|c|c|c|}
\hline \multirow{2}{*}{$\begin{array}{l}\text { Spezifitäten } \\
\text { Anti- }\end{array}$} & \multirow[t]{2}{*}{ Serum } & \multicolumn{2}{|l|}{ Titer } & \multirow[t]{2}{*}{ Kommentar } \\
\hline & & Standardtechnik & Modifikation & \\
\hline $\begin{array}{l}A \\
B \\
A \\
M \\
N\end{array}$ & $\begin{array}{l}1: 200 \\
1: 200 \\
1: 200 \\
1: 32 \\
1: 32\end{array}$ & $\begin{array}{l}1: 2 \\
1: 2 \\
1: 2 \\
1: 4 \\
1: 2\end{array}$ & $\begin{array}{l}1: 2 \\
1: 2 \\
1: 2 \\
1: 4 \\
1: 2\end{array}$ & \multirow[t]{2}{*}{$\begin{array}{l}\text { Orig. Serum 1:40 } \\
\text { Orig. Serum 1:20 } \\
\text { Orig. Serum 1:40 } \\
\text { Modif. zeigt schwächere } \\
\text { Agglutinate }\end{array}$} \\
\hline $\begin{array}{l}M \text { (monokl.) } \\
N \text { (monokl.) } \\
D \\
E \\
C D \\
C \\
\text { e } \\
\text { C } \\
\text { Fy }\end{array}$ & $\begin{array}{l}1: 32 \\
1: 32 \\
1: 2048 \\
N T \\
1: 1024 \\
1: 128 \\
1: 128 \\
N T \\
1: 128\end{array}$ & $\begin{array}{l}1: 8 \\
1: 4 \\
1: 64 \\
1: 16 \\
1: 32 \\
1: 32 \\
1: 16 \\
1: 4 \\
1: 16\end{array}$ & $\begin{array}{l}1: 8 \\
1: 4 \\
1: 64 \\
1: 32 \\
1: 32 \\
1: 32 \\
1: 16 \\
1: 4 \\
1: 16\end{array}$ & \\
\hline $\begin{array}{l}\text { Fy } \\
\text { Jk }\end{array}$ & $\begin{array}{l}1: 256 \\
1: 16\end{array}$ & $\begin{array}{l}1: 16 \\
1: 1\end{array}$ & $\begin{array}{l}1: 16 \\
1: 1\end{array}$ & Originalserum schwach \\
\hline
\end{tabular}

- i.C. = indirekter Coombstest

stäbchen durchmischen); Zentrifugation bei $3000 \mathrm{UpM}$ 5 min; abpipettieren des Überstands (= Eluat).

Die zum modifizierten Eluat verwendeten Erythrozyten werden $2 \mathrm{mal}$ in PBS gewaschen und danach in einer Ammoniumchloridlösung lysiert: $1,5 \mathrm{ml}$ Erythrozytensediment plus $8,5 \mathrm{ml}$ Ammoniumchloridlösung $5 \mathrm{~min}$ bei $0^{\circ} \mathrm{C}$; Zentrifugation $5 \mathrm{~min}$ bei $3500 \mathrm{UpM}$; abheben der oberen Hälfte des Lysats; Ergänzung des entnommenen Volumens mit PBS; 3maliges Waschen der teil-lysierten Erythrozyten in PBS (Zentrifugation jeweils 3500 UpM $5 \mathrm{~min}$ ).

\section{Hämagglutination}

$100 \mu \mathrm{l}$ Serum oder Eluat werden $50 \mu \mathrm{l}$ einer $5 \%$ (V/V) Erythrozytensuspension in $0,9 \% \mathrm{NaCl}$ zugesetzt. Die Inkubation erfolgt bei agglutinierenden Antikörpern (ABO, $\mathrm{MN}$ ) in geometrischen Verdünnungsreihen auf einer Glasplatte $\left(14^{\circ} \mathrm{C}\right.$ Kaltwasserdurchlaufplatte); coombsreaktive Eluate der Spezifitäten Anti-Rhesus, Duffy, Kidd werden im Röhrchen unter Zusatz von $100 \mu$ LISS 15 min bei $37^{\circ} \mathrm{C}$ inkubiert, 3mal in PBS gewaschen, mit $100 \mu \mathrm{l}$ polyspezifischem Coombsserum versetzt. Das Ergebnis wird nach Zentrifugation $1 \mathrm{~min}$ bei $500 \times \mathrm{g}$ abgelesen.

\section{Ergebnisse}

Wie aus Tab. 2 hervorgeht, sind die Titer-Ergebnisse des herkömmlichen Chloroformeluats mit jenen des modifizierten zwar praktisch identisch, gleichzeitig aber zeichnet sich das modifizierte Eluat durch das Fehlen einer Verfärbung durch Hämoglobin und eine scharfe Trennlinie gegen den Zelldetritus aus. Die im Interesse geringer Raumluftkontamination erforderliche Entfernung des Chloroforms läßt sich bei Röhrchen, die für das modifizierte Eluat Verwendung fanden, einfach durchführen, beim herkömmlichen Eluat jedoch nicht, da sich dessen Zelldetritus mit üblichen Laborpumpen nicht absaugen läßt.

\section{Diskussion}

Während sich eine Elution durch Senkung des $\mathrm{pH}$-Wertes oder durch Kälteschock nicht zur Absprengurig aller Äntikörperspezifitäten bzw. -klassen eignet (6), trifft dies bei
Elutionstechniken mittels organischer Lösungsmittel und der thermischen Absprengung nach Landsteiner zu (6, 7). Wir verwenden als Lösungsmittel Chloroform, weil es nicht explosiv ist.

Der Nachteil von Chloroformeluaten war jedoch bisher die starke Verfärbung des Eluats durch Hämoglobin. Durch die beschriebene Modifikation sind auch schwache Agglutinationen im Eluat noch erkennbar, was bei stark hämolytischen. Eluaten nicht immer der Fall ist. Durch die Behandlung mit Ammoniumchlorid tritt eine Teillyse ein, das Hämoglobin wird durch mehrmaliges Waschen entfernt und man erhält ein klares, unverfärbtes Eluat. Eine Titerverminderung tritt durch die Modifikation nicht ein, die gewonnene Eluatmenge ist meist etwas größer als bei der Standardtechnik (siehe Tab. 2).

Während erythrozytäre Antikörper der IgG-Klasse mittels indirektem Coombstest unbeeinflußt vom Hämolysegrad des Eluats leicht zu erkennen sind, behindert bei lgMAntikörpern Hämoglobin die Diagnostik. Durch die beschriebene Modifikation ist dieser Nachteil behoben. Bei Elutionsuntersuchungen mit IgM Antikörpern, wie sie z. B. in der Diagnose schwacher Antigene im ABO-System durchgeführt werden, ist dies von besonderem Vorteil.

Schrifttum:

1. BRANCH, D. R., SY SIOK HAN, A., PETZ, L. D.: A new elution technique using chloroform, an non flammable organic solvent. Vox Sang. 42, 46-83 (1982).

2. BUENO, R., GARRATY, G., POSTOWAY, N.: Elution of antibody from red cells using xylene. A superior method. Transfusion 21, 157-167 (1981).

3. EICHER, C.: The LUI easy freeze elution test: A rapid method for eluting cord samples. South East Ass. Blood Banks J. 199 (1976).

4. JENKINS, D. E., MOORE, W. H.: A rapid method for the preparation of high potency of auto- and alloantibody eluates. Transfusion 17, 110-114 (1977).

5. LANDSTEINER, K., MILLER, C. P.: Serological studies on the blood of primates. II. The blood of anthropoid apes. J. Exp. Med. 42, 853-862 (1925).

6. NESPITAL, H., SACHS, V.: Zur Effizienz verschiedener Methoden der Absprengung von antierythrozytären Antikörpern. 10. Bremer Bluttransfusionsgespräche, 40-55 (1983).

7. PANZER, S., SALAMA, A., BODEKER, R. H., MÜLLER-ECKHARDT, C.: Quantitative evaluation of elution methods for red cell antibodies. Vox Sang 46, 330-335 (1985). '

8. PETZ, L. D., BRANCH, D. R.: In: Immune Cytopenias, ed. by R. MacMillan Churchill Livingstone (1984) Serological tests for the diagnosis of immune haemolytic anaemias Methods in Hematology, Vol. 9, 9-48 (1983).

9. RUBIN, H.: Antibody elution from red blood cells. J. Clin. Path. 16. 70-73 (1963).

Anschrift des Verfassers:

Dr. Peter. M. Winter

Institut für Blutgruppenserologie der Universität Wien

Spitalgasse 4, A-1090 Wien 


\section{Der neuse Weg zur Automatisierung in klinischer Chemie und Immunologie}

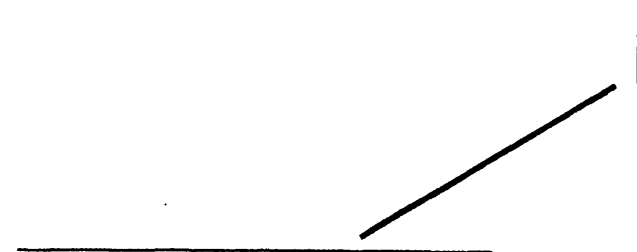

eagaspatia
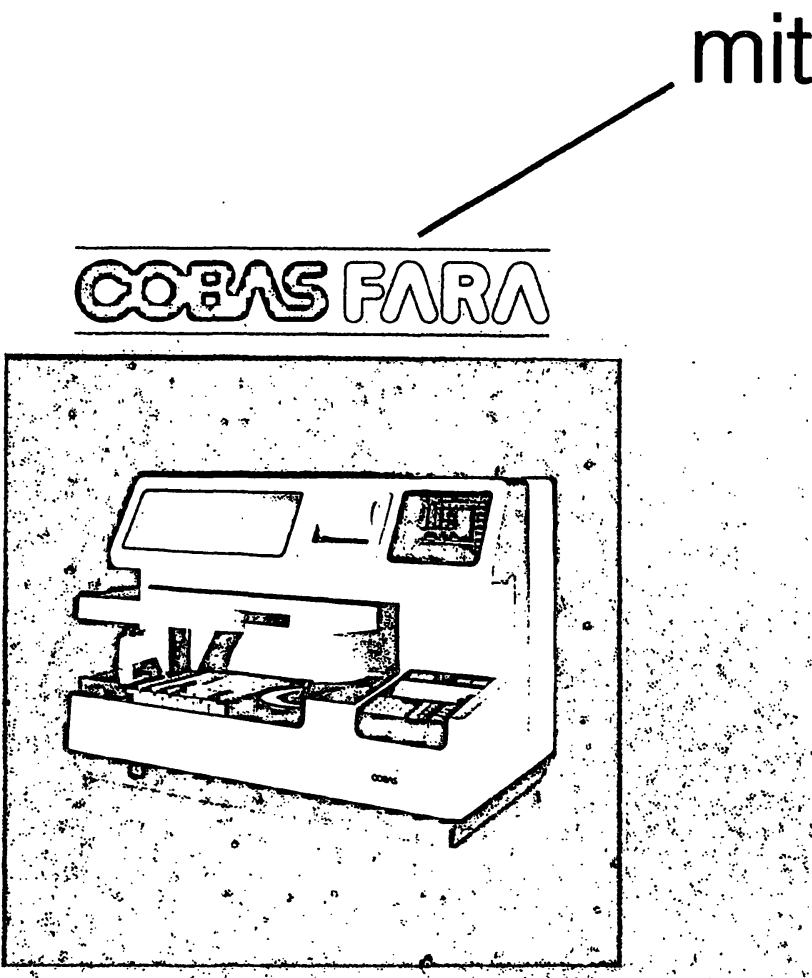

Selektiv-Zentrifugalanalysator

Routine und Spezialanalysen
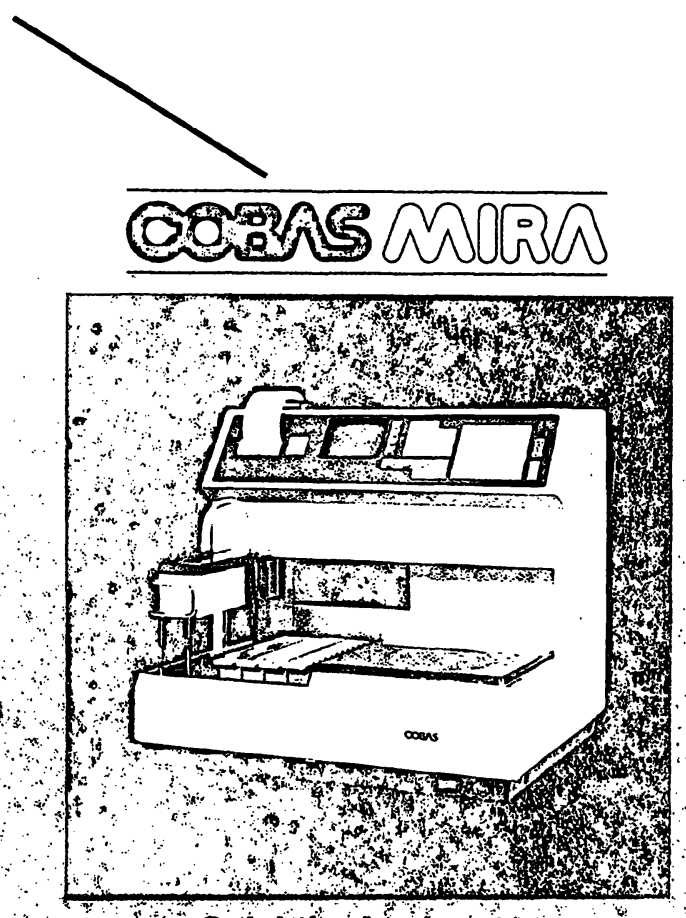

Selektiv-Analysatór

für

keine und mittlere Serien:

Back-upi-Tests

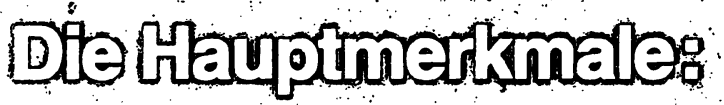

0 Wahltreler Zurgang zu Probnumd Reagenzlen

Q Guerschledene Standermodelle (Racks)

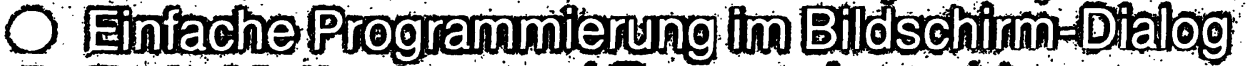

O Fielle Methodenp und Reagenztentwalin.

O Niédere Betriebskosten

0 Rouftne- und Noffalltaug liteh 


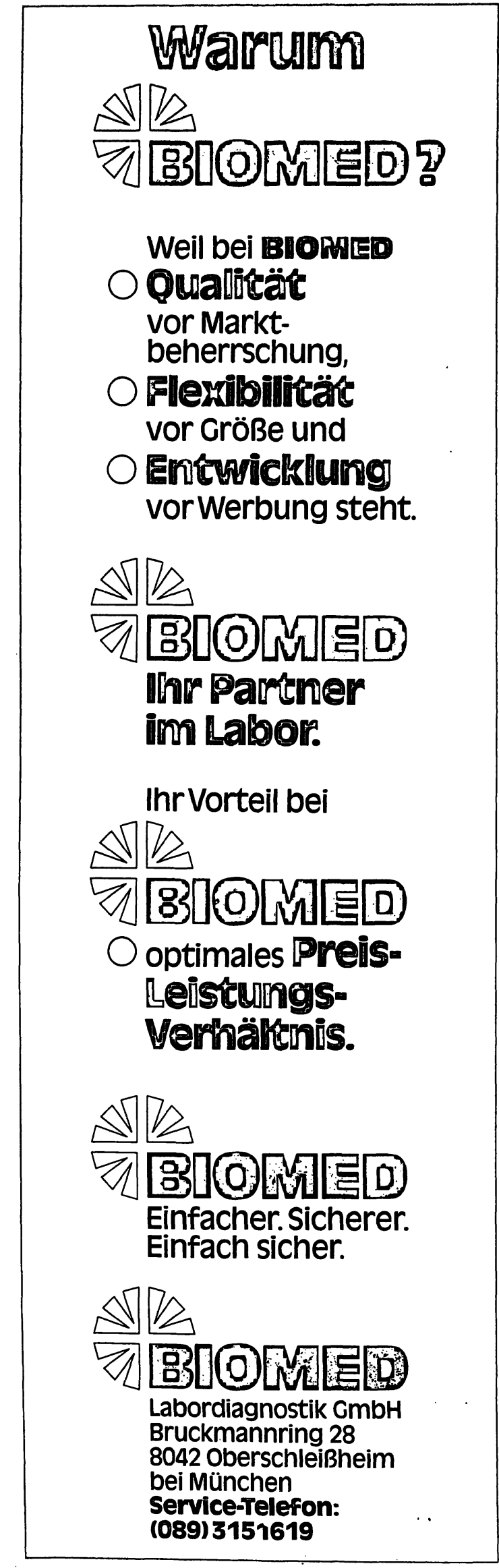

\section{Verunsichert?}

inch oder $\mathbf{c m}$

läßt die Entfernung unbeeindruckt,

$\mathbf{H b A}_{1 \mathrm{c}}$ oder $\mathbf{H b A}_{\mathbf{I}}$ die Stoffwechsellage unbeeinflußt.

$\mathbf{H b A}_{\mathrm{I}}$ ist das metrische $\mathrm{Maß}$ der Langzeitkontrolle Ihrer Diabetiker oder wollen Sie umrechnen?

GLYC-AFFIN - die affinitätschromatographische Methode der Wahl zur Erfassung aller $\mathbf{G H b}$ 's oder Glycoproteine, auch bei abnormen Hämoglobinmustern oder Temperaturproblemen.

Auch hier sind wir innovativ und haben den Vorsprung.

FAST Hb TEST SYSTEM mit

ALDIMIN ELIMINATOR VERIFICATOR

und Glyc-Affin gibt es für 20 und 100 Bestimmungen.

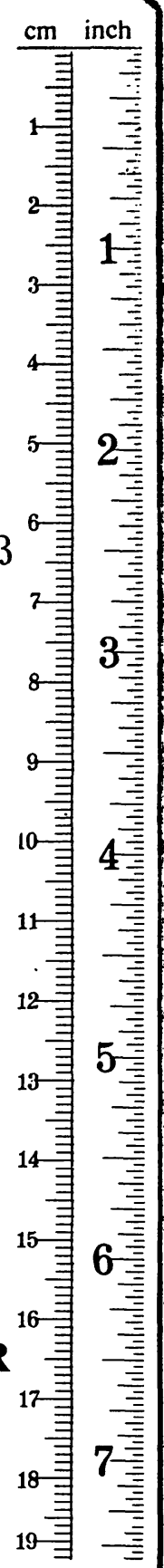

Bezug und Information durch:

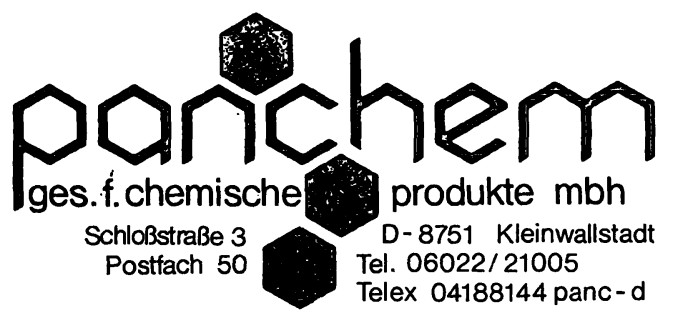

